\title{
Effect of Carbon Fibre Reinforced Polymer Strengthening on the Axial Capacity and Ductility of Non-slender Square Concrete Columns
}

\author{
Muthomi Munyua*, Siphila Mumenya, John Mwero \\ School of Engineering, University of Nairobi \\ P. O. Box 30197 - 00100, Nairobi, Kenya. \\ *Corresponding author: muthomi@uonbi.ac.ke
}

\begin{abstract}
This research investigated the effect of Carbon Fibre Reinforced Polymer (CFRP) strengthening on the axial capacity and ductility of non-slender square concrete columns. There was a problem of buildings collapsing in Kenya. Retrofitting of the buildings vulnerable to collapse was of great importance to ensure the safety of the occupants and to address the housing deficit in the country. An experimental research programme was conducted on 90 non-slender square concrete columns to find out the gain in axial capacity and ductility of the columns strengthened by CFRP. The specimens $(150 \mathrm{~mm} \times 150 \mathrm{~mm} \times 350 \mathrm{~mm})$ were made of plain and reinforced concrete. Three different concrete grades: C8/10, C12/15 and C16/20 were used. The specimen had varying configurations of CFRP wrap: partial and full confinement in one and two layers. Four parameters were investigated in this study: concrete grade, steel reinforcement, degree of confinement and the number of layers of CFRP wrap. The specimens were subjected to uniaxial compression up to failure, and the stress-strain curves were plotted. This study found that weaker concrete grades experienced the highest effect due to CFRP strengthening. Presence of reinforcement had a significant effect on the axial capacity and ductility of columns without CFRP strengthening. On the contrary, the presence of steel reinforcement reduced the effectiveness of CFRP strengthening. Partial CFRP confinement offered better material efficiency as compared to full CFRP confinement, and the number of layers had a direct relationship with the increase in strength and ductility.
\end{abstract}

Keywords: Carbon Fibre Reinforced Polymer Wrap, Non-slender columns, retrofitting, axial capacity, ductility, CFRP, confinement, square concrete columns

\section{Introduction}

Reinforced concrete (RC) columns are composed of concrete and steel reinforcement. Concrete is the material that bears most of the compressive stresses while steel reinforcement bears most of the tensile stresses in the column [1]. The manufacture of concrete is influenced by numerous factors that lead to significant variability in its strength. RC columns may not attain the target strength when manufactured on site. Failure to attain the target strength may lead to difficulties such as higher deflections than estimated, cracking or even complete failure by crushing or buckling.

To determine the strength of the cast-in-place concrete, sample cubes are usually made and tested by the cube crushing method, according to BS EN 12390-2:2009 [2]. Demolition is recommended for concrete that is not up to standard. An alternative option to avoid demolition is retrofitting with Carbon Fibre Reinforced Polymer wrap or steel angles.

Kenya has experienced several building collapses [3]. In 2015, the National Construction Authority (NCA) found that $58 \%$ of buildings in Nairobi were unfit for habitation. That NCA building audit reported that eight buildings collapsed and killed 15 people in that year [4]. This statistic is comparable to an audit report three years later by Nairobi City County that showed that $44 \%$ of buildings were unsafe [5]. Nevertheless, there is limited knowledge and guidance for conducting such retrofits with regards to CFRP [6]. The lack of guidance or design codes has led to a reluctance to adopt CFRP strengthening by engineers and owners. This research addressed this problem by investigating four variables to improve the understanding of CFRP strengthening in columns.

The overall objective of this study was to investigate the effect of CFRP strengthening on the axial capacity and ductility of non-slender square concrete columns. The specific objectives were:

1. To determine the contribution of CFRP strengthening on three different concrete grades to the axial capacity and ductility of non-slender square concrete columns.

2. To quantify the effect of CFRP strengthening on plain and reinforced concrete on axial capacity and ductility of non-slender square columns.

3. To compare the effect of full CFRP confinement and partial CFRP confinement to the axial capacity and ductility of non-slender square concrete columns.

4. To determine the effect of additional layers of CFRP on axial capacity and ductility of non-slender square concrete columns. 
This study is essential as it may provide the necessary guidance to structural engineers when using CFRP strengthening:

1. To increase the load-bearing capacity of a structure, for example, the addition of new floors or change of use from residential to commercial.

2. To add reinforcement to a structure that is already under-designed or wrongly constructed.

3. To develop a better understanding and consequently to leverage this understanding to fine-tune the parameters in the structural design process.

The axial capacity and ductility of columns were the only dependent variables to be investigated. The scope of the study was restricted to non-slender concrete columns under concentric loading. The loading had no eccentricity; therefore, failure would only occur once the maximum axial capacity of the columns was attained. The specimen height was limited by the maximum clearance of the compression test machine, which consequently governed the cross-section dimensions to ensure the column would be categorised as non-slender. The maximum number of layers to be used was two to minimise the cost of the experimental programme. The grades of concrete chosen: $\mathrm{C} 8 / 10$, C12/15 and C16/20 were the grades below the concrete commonly used for structural purposes. That typical concrete grade used for structural purposes is C20/25 [7].

Fibre composites such as CFRP have been applied in other disciplines of engineering such as automotive and aerospace. In structural engineering, fibre composites have been used in aggressive environments such as factories to offer protection against chemical attack [6], [8]. This study did not look into such applications; it focused on the strengthening of concrete structures using CFRP bonded to the surface of the columns.

There are scenarios in which the axial capacity of a structure may need to be increased. Such scenarios include: the change of use of a building, where substandard materials were used, or where the structure was damaged. Steel plates or CFRP may be used to achieve this. According to The Concrete Society [6], the techniques developed about the year 2000 for CFRP strengthening used similar principles as for steel plate bonding. CFRP is advantageous to steel plates in this application; in that they can be used in circumstances where it would be impractical to use steel. For example, CFRP is very flexible and can be formed into complicated shapes, unlike steel. CFRP is very light as compared to steel, and last of all is that CFRP is easily cut to length on site [9].

When a vertical concrete column is subjected to uniaxial compression, the concrete deforms by a contraction in the longitudinal direction as it expands in the transverse direction. This phenomenon is known as Poisson's effect.

The lateral expansion results in tension in the column. Concrete has low tensile strength capacity; hence the tension developed leads to failure of the column. When CFRP resists this lateral expansion, the concrete is changed to a three-dimensional compressive stress state. In this state, the performance of the concrete column is significantly influenced by the confinement pressure [10]. CFRP strengthening works by providing external confinement to the column, thus limiting the lateral expansion. Confinement, therefore, affects the stress-strain behaviour of standard concrete. The concrete grade and the reinforcement affect the lateral expansion while the degree of confinement and number of layers restricts the lateral expansion. Other studies have been conducted and the findings are presented.

\subsection{Concrete Grade}

Shrive et al. [11] used a simple analysis of circular columns, performed finite element analysis of a chamfered column and concluded that the confining effect of the wrap was not engaged until the concrete started failing and dilating. The strain readings analysed confirmed the conclusion arrived at; columns composed of weaker strength grades fail at lower axial stress and dilate more than columns of stronger concrete grades. This higher dilation will cause higher lateral pressures and more confining effect on the weaker columns resulting in an increased axial capacity gain. It was found that strength gains can be expected to reduce with increasing strength of the concrete. The finding showed that there is an inverse relationship between concrete strength grade and an increase in gain in strength.

\subsection{Reinforcement}

Shrive et al. [11] investigated reinforced and prestressed concrete columns with one or two layers of CFRP wrap to failure in axial compression. This study found the predictions of two proposed design methods consistently underestimated actual failure loads and that the design procedure was thus conservative. That study did not investigate CFRP strengthening on plain concrete.

\subsection{Degree of confinement}

The work of Richart et al. [12] on triaxially confined concrete based on tests on cylindrical specimens subjected to constant hydrostatic pressure showed that both axial strength and ductility of concrete increases with increasing confinement pressure. CFRP strengthening utilises this principle. The studies reviewed utilised full confinement [11], [13]-[20]. This study found few studies where partial confinement was used [21], [22]. Further investigation was made by this research programme to find out the effect of reducing 
the CFRP wrap for economic purposes based on the manufacturer's claims, as shown in Figure 1.1. Partial confinement also had the advantage of easier and faster application [22].

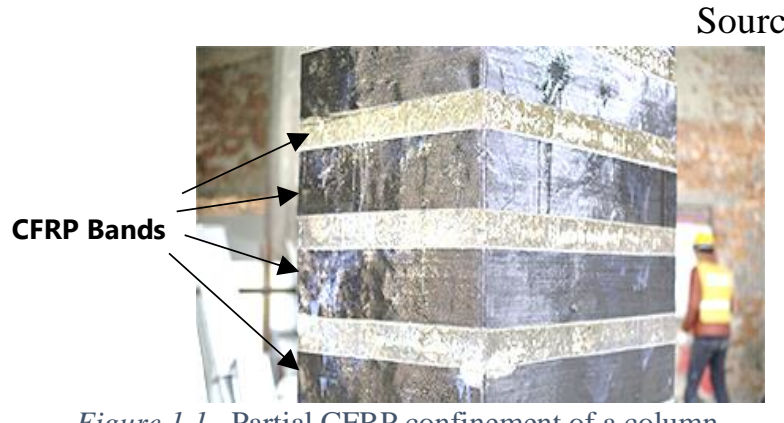

Figure 1.1. Partial CFRP confinement of a column.

A study of partial confinement by Guo and Zeng [22] only looked at axial behaviour and did not look at the ductile behaviour of partially confined columns.

\subsection{CFRP Thickness}

CFRP thickness has substantial effects on the strength and ductility of repaired columns [24]. Thickness was directly related to the exerted confinement pressure of the FRP jacket as the confinement effectiveness increases with the higher thickness [25].

Saafi et al. [26] tested non-slender concrete columns confined with FRP tubes under uniaxial compressive load to investigate the effects of FRP jacket thickness in addition to fibre type and concrete strength. It was reported that FRP jacket thickness has a direct relationship with the increase in axial capacity and ductility of the columns. Rochette and Labossière [20] axially tested the effect of wrap thickness and crosssection shape of non-slender columns on its strength and also came to similar conclusions; CFRP thickness increases axial capacity and ductility.

Parvin and Wang [19] performed an experimental and numerical analysis of FRP jacketed square concrete columns under eccentric loading. Later, Parvin and Jamwal [18] investigated small-scale FRP wrapped concrete cylinders under uniaxial compressive loading through nonlinear finite element analysis. This subsequent investigation found that an increase in wrap thickness had a positive change on axial strength and ductility of the concrete cylinders. The results from the two separate studies thus showed that the strength and ductility of concrete columns could significantly increase due to CFRP strengthening [18], [19].

Shehata et al. [27] conducted an experimental research programme that included tests on 54 non-slender columns to find out the gain in axial capacity and ductility of concrete columns externally confined by CFRP wrap. The variables studied in the programme were column cross-section shape and the amount of confinement expressed in the number of CFRP sheets applied to the specimen. The number of layers was limited to a maximum of two. Shrive et al. [11] investigated the effect of wrap thickness and showed that whereas strength gain is directly related to CFRP wrap thickness, the relationship is not linear.

\subsection{Column shape}

Most of the available studies on the behaviour of FRP confined concrete columns have focused on circular columns, while relatively few studies have looked into rectangular columns [28]. The column given in Figure 3.6 of the Eurocode, EN 1992-1-1:2004, is that of a cylindrical specimen with a circular cross-section. The bias on circular columns is somewhat because a square section is not uniformly confined, and the compressive pressure is unevenly distributed.

Nanni and Bradford [17] test specimens consisted of $150 \times 300 \mathrm{~mm}$ high cylinders to verify existing analytical models. Their experimental results indicated that the FRP jackets increased the ductility and strength significantly. Mirmiran et al. [29] also used cylinders which had FRP jackets and found that there was a significant increase in axial capacity and ductility. Their findings indicated that, as the jacket thickness increased, the strength and ductility increased as well.

In square and rectangular cross-sections, the stressstrain curve is affected by the radius to which the corners of the sections are rounded off in order to avoid the breakage of fibres. Rounding of corners leads to a reduction in cross-section area leads to a corresponding decrease in axial capacity. This reduction in strength may lead to catastrophe for buildings already vulnerable to collapse. This research programme did not round the corners of the square columns. Failure to round the corners of square columns would have the effect of reduced confined area [16].

Despite the effectiveness of CFRP confinement in circular columns, square columns are usually preferred because of ease in the fabrication of formworks, constructability and architectural reasons [21], [22].

\subsection{Size of columns}

Masia et al. [16] investigated the size effects of square columns. That study found significant effects in axial capacity and ductility were achieved by wrapping. The effectiveness of the wrap, as measured by the percentage increases in strength and peak axial strain, reduced with increasing cross-sectional size.

\subsection{Summary of previous studies}

Several studies [15], [17], [29] used circular cylinders, whereas this research used square columns. Previous research has a bias to circular columns which have a higher degree of confinement than in square columns as evidenced in the study by Masia et al. [16]. 
The design procedure advocated by Eurocode 2 (EN 1992-1-1) assumes that the lateral pressure is known and constant however other literature shows that the confining effects of the wrap are not engaged until the concrete fails and dilates causing confinement pressure that varies with the deformation experienced in the concrete [11].

Most equations provided in literature [6] do not have a variable to cater for the effect of thickness of the CFRP wrap or the confining material and the design methods use the simple extension of the models developed for conventional reinforced concrete columns [29].

An accurate prediction of the stress-strain curve of composite confined concrete is rather complex to obtain due to the high number of variables that affect the model [27]. With this realisation and despite extensive work on CFRP on concrete columns, there is little research with regards to the effect of CFRP on non-slender columns when comparing:

1. Concrete strength grades.

2. Plain and reinforced concrete.

3. Partial and full confinement.

The conceptual framework was as shown in Figure 1.2.

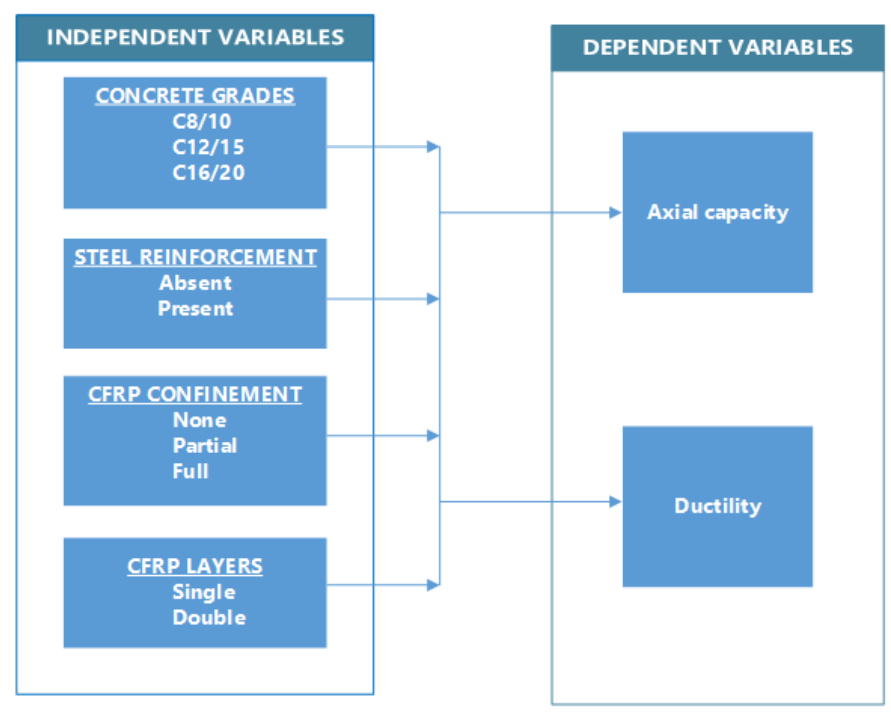

Figure 1.2. Conceptual Framework.

\section{Materials and Methods}

\subsection{Experimental investigation}

Ninety column samples were manufactured and tested to investigate the effects of concrete grade, steel reinforcement, degree of confinement and number of CFRP layers.

\subsubsection{Independent variables of the study}

\subsubsection{Concrete grades used in the study}

This experimental programme used three strength grades of concrete C8/10, C12/15 and C16/20 for the specimens as per the first research question. There were 30 specimens for each grade of concrete. Three samples were made for each specimen. These concrete grades were selected because of their lower characteristic strength than Concrete C20/25. Any retrofits in this experiment attempted to attain the characteristic strength of concrete $\mathrm{C} 20 / 25$.

\subsubsection{Presence of Steel Reinforcement}

Of the 90 specimens, 45 had no steel reinforcement while the remaining 45 had steel reinforcement.

\subsubsection{Degree of confinement}

With regards to the various configurations of CFRP confinement, 36 specimens with partial CFRP confinement and 36 specimens with full CFRP confinement were manufactured. Eighteen specimens did not receive any application of CFRP. The 18 specimens without CFRP treatment were used as the control for this comparative study.

\subsubsection{Number of layers}

To find out the effect of the number of layers, 18 of the 36 specimens with partial CFRP confinement had one layer of the CFRP wrap, and the remaining 18 had two layers of CFRP wrap. Eighteen of 36 specimens with full confinement had one layer of CFRP wrap, and the remaining had two layers of CFRP wrap. The 18 specimens without CFRP wrap were used as the control.

\subsubsection{Dependent variables of the study}

A compression test machine axially loaded the specimen to failure. The loading rate was not constant but was manually controlled as per the procedure described in BS EN 12390-3: 2019 [30].The failure load and deflections were recorded and were used to calculate the axial capacity and ductility of the column specimens.

\subsubsection{Determination of the axial capacity of the columns}

The axial capacity was measured as the maximum load the column could withstand before the failure occurred. The maximum load was divided by the cross-section area to determine the axial capacity.

$$
\text { Axial capacity }=\frac{\text { Load at failure }}{\text { Area of colum cross }- \text { section }}
$$

\subsubsection{Determination of the ductility of the columns}

As the specimen was loaded, the longitudinal deflections were measured using a strain gauge. The deflections with the corresponding loads that caused those deflections were recorded. Ductility was calculated as the final longitudinal deformation expressed as a percentage.

$$
\text { Ductility }=\frac{\text { Deflection at failure }}{\text { Initial length of column }} \times 100 \%
$$




\subsubsection{Specimen Details}

Ninety column specimens were manufactured in various configurations presented in Table 2.1. Specimens A and B had no CFRP strengthening as shown in Figure 2.1 (a). Specimens A and B were the control specimen.

Table 2.1. Composition matrix of specimens manufactured.

\begin{tabular}{|c|c|c|c|c|c|}
\hline $\begin{array}{c}\text { Specimen } \\
\text { Type }\end{array}$ & $\begin{array}{l}\text { No of } \\
\text { samples }\end{array}$ & Rebar & $\begin{array}{l}\text { Partial } \\
\text { CPRF }\end{array}$ & $\begin{array}{c}\text { Full } \\
\text { CFRP }\end{array}$ & $\begin{array}{l}\text { CFRP } \\
\text { Layers }\end{array}$ \\
\hline $\mathbf{A}$ & 3 & $x$ & $x$ & $x$ & 0 \\
\hline B & 3 & $\checkmark$ & $x$ & $x$ & 0 \\
\hline C & 3 & $X$ & $\checkmark$ & $x$ & 1 \\
\hline D & 3 & $\checkmark$ & $\checkmark$ & $x$ & 1 \\
\hline $\mathbf{E}$ & 3 & $X$ & $x$ & $\checkmark$ & 1 \\
\hline $\mathbf{F}$ & 3 & $\checkmark$ & $x$ & $\checkmark$ & 1 \\
\hline G & 3 & $x$ & $\checkmark$ & $x$ & 2 \\
\hline H & 3 & $\checkmark$ & $\checkmark$ & $x$ & 2 \\
\hline I & 3 & $x$ & $x$ & $\checkmark$ & 2 \\
\hline $\mathbf{J}$ & 3 & $\checkmark$ & $x$ & $\checkmark$ & 2 \\
\hline
\end{tabular}

Specimens C, D, $\mathrm{G}$ and $\mathrm{H}$ had partial CFRP confinement as shown in Figure 2.1 (b) while Specimens E, F, I and J had full CFRP as shown in Figure 2.1 (c).

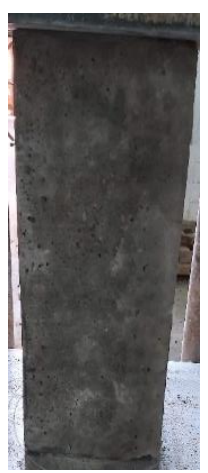

(a)

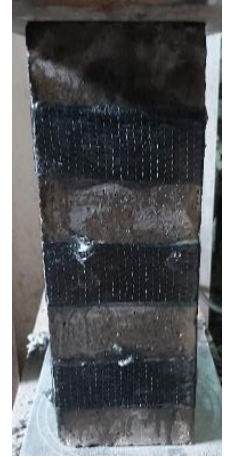

(b)

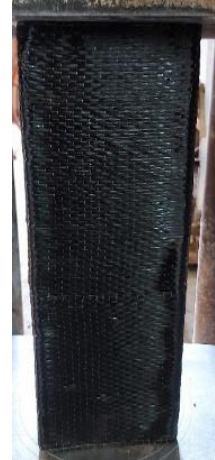

(c)
Figure 2.1. Pictures of manufactured specimens.

Specimens C, D, E and F had one layer while Specimens G, H, I and J had two layers of CFRP wrap. All the specimens with CFRP wrap had a $150 \mathrm{~mm}$ overlap to prevent lap joint failure due to debonding [6].

\section{Results \& Discussions}

\subsection{Mechanical properties of the columns}

The mechanical properties of the columns are the physical properties that the columns exhibited during the testing. The physical properties of the column analysed were the axial capacity and ductility. The data from the testing process was recorded and analysed. The analysis is first organised by concrete grade, then by rebar, followed by the degree of confinement and finally by the number of layers. This reorganisation of the results facilitated identification and visualisation of trends.

\subsubsection{Axial Capacity of Specimen}

The values of the axial capacities of the specimens are presented in Table 3.1.

\begin{tabular}{|c|c|c|c|}
\hline \begin{tabular}{c} 
Table 3.1. Results for the axial capacity of specimens. \\
\hline $\begin{array}{c}\text { Specimen } \\
\text { Type }\end{array}$
\end{tabular} & $\mathbf{C 8 / 1 0}$ & $\mathbf{C 1 2 / 1 5}$ & $\mathbf{C 1 6 / 2 0}$ \\
\hline A & 7.9 & 13.2 & 17.5 \\
\hline B & 9.8 & 14.8 & 18.4 \\
\hline C & 8.0 & 16.4 & 19.3 \\
\hline D & 10.1 & 18.7 & 19.3 \\
\hline E & 9.0 & 14.7 & 19.4 \\
\hline F & 10.2 & 18.7 & 20.9 \\
\hline G & 13.5 & 14.5 & 18.2 \\
\hline H & 15.6 & 15.1 & 18.5 \\
\hline I & 20.6 & 18.4 & 23.0 \\
\hline J & 25.6 & 21.8 & 20.6 \\
\hline
\end{tabular}

The average values of Specimens C, D, E, F, G, H, I and $\mathrm{J}$ were compared with Specimens A and B to find out the effect of concrete grade.

\subsubsection{Effect of Concrete grade on axial capacity of CFRP strengthened columns}

The results for axial capacity based on the different concrete grades are presented in Figure 3.1.

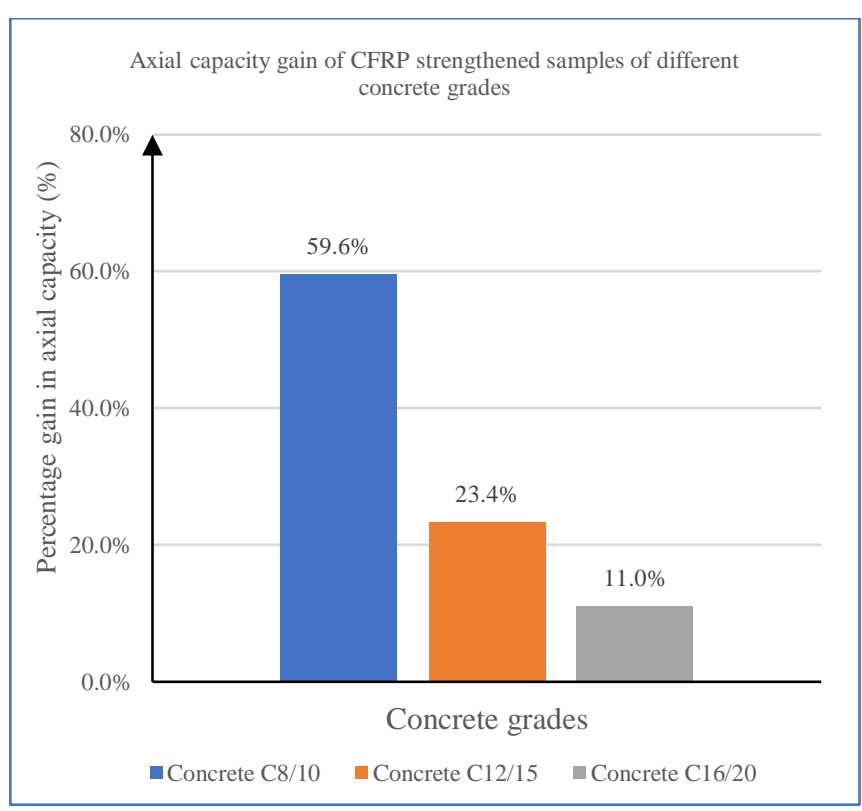

Figure 3.1. Effect of Concrete grade on axial capacity of CFRP strengthened samples.

The chart shows that with all the other variables not taken into consideration, Concrete C8/10 experienced the highest effect when CFRP wrap was installed. The experimental investigation found that concrete grade affected the gain in axial capacity. This analysis, therefore, confirms the findings by Shehata et al. [27] that weaker grades of concrete develop the most tremendous change in axial capacity when strengthened by CFRP. 


\subsubsection{Effect of rebar on axial capacity of CFRP strengthened columns}

To find out the effect on rebar on axial capacity four comparisons were made and are presented in Figure 3.2.

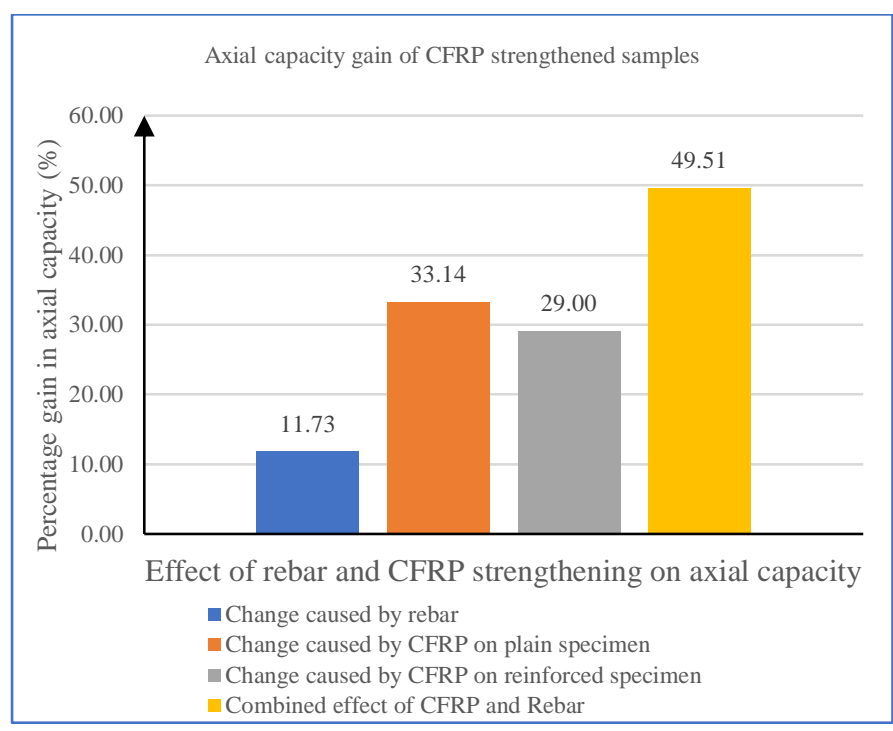

Figure 3.2. Effect of rebar and CFRP on axial capacity of CFRP strengthened samples.

The first bar shows the change in axial capacity of reinforced concrete strengthened with CFRP compared against plain concrete specimens strengthened with CFRP. Rebar caused an increase $(11.73 \%)$ in the strength. The second bar shows the change (33.14\%) in axial capacity of plain concrete specimen with CFRP strengthening compared with plain concrete specimen without CFRP strengthening. It is evident that CFRP strengthening increased the axial capacity of the specimens. The third bar shows the comparison (29\%) between reinforced concrete specimens with CFRP and reinforced concrete specimens without CFRP. Again, the CFRP increased the axial capacity of the reinforced concrete specimens. The fourth bar shows the comparison $(49.51 \%)$ between reinforced concrete specimens with CFRP strengthening and plain concrete specimens. The last graph represents the combined effect of both rebar and CFRP strengthening on the axial capacity.

There is a slight difference between the effect of CFRP strengthening on the axial capacity of plain and reinforced concrete. Reinforced concrete specimen had less gain in strength due to CFRP strengthening as compared to plain concrete. This was attributed to the fact that the reinforcement reduced the lateral expansion of the concrete and thus less passive pressure was generated on the CFRP. The less passive pressure led to the less gain in axial capacity.

The sum of the gain in axial capacity due to the individual effect of rebar (11.73\%) and the individual effect of CFRP (33.14\%) was $44.87 \%$. From the chart again, the average gain in axial capacity due to the combined effect of both rebar and CFRP strengthening was $49.51 \%$. Comparison of the final calculated values and from the inspection of the chart in Figure 3.2, it is evident that the combined effect of CFRP strengthening and rebar on axial capacity is comparable to the sum of the individual effect of rebar and the individual effect of CFRP strengthening. This realisation is vital as it provides a rationale to which engineers can determine the combined effect of CFRP strengthening and rebar to the axial capacity of RC columns.

\subsubsection{Effect of Degree of Confinement on axial capacity of CFRP strengthened columns}

The comparison of partial and full CFRP confinement is presented in Figure 3.3.

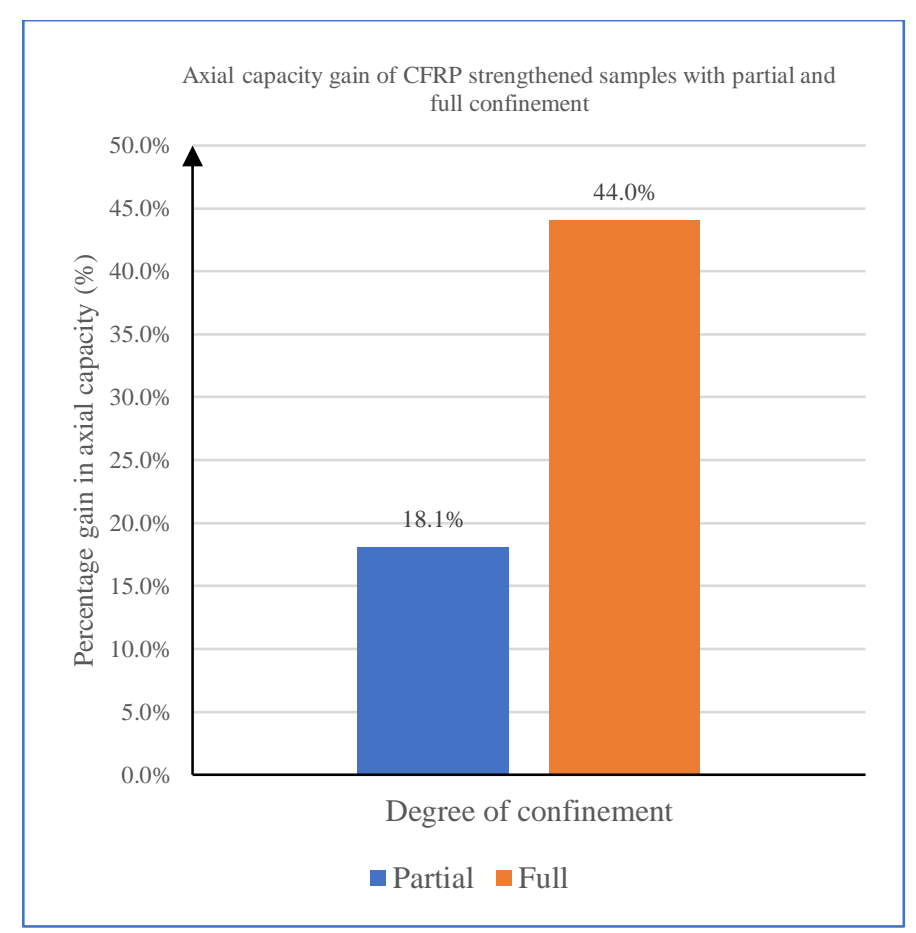

Figure 3.3. Effect of degree of confinement on axial capacity of CFRP strengthened columns.

Full CFRP confinement offers more passive pressure as the column dilates hence a higher axial capacity than partial CFRP confinement [21]. The claim that partial confinement offers the same benefit as full CFRP confinement was therefore disproved [23].

Full CFRP confinement should therefore be used whenever higher increases in strength are required. In situations where small increases in axial capacity are required, partial confinement serves as a viable solution. 


\subsubsection{Effect of number of layers on axial capacity} of CFRP strengthened columns

The effect of the number of layers on axial capacity was compared in Figure 3.4.

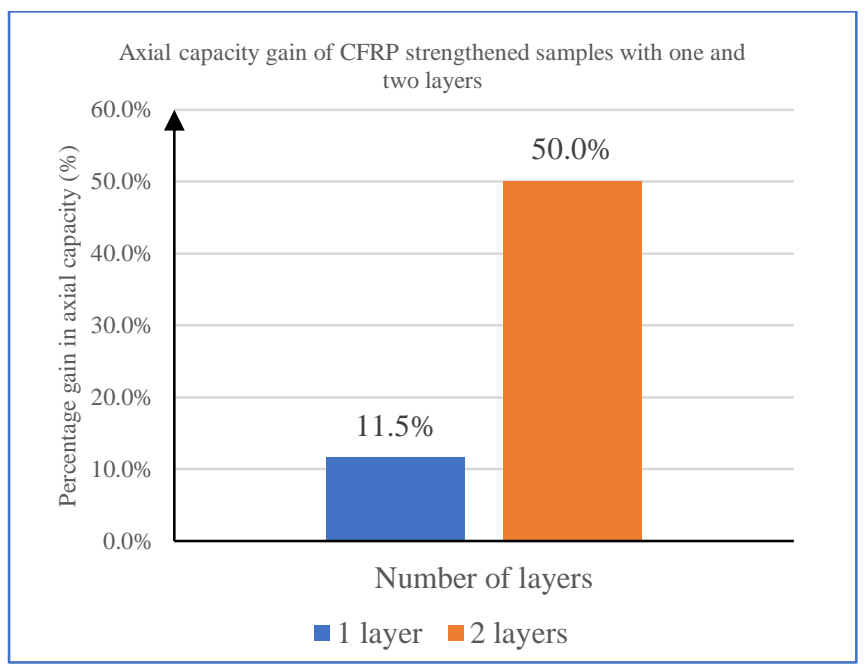

Figure 3.4. Effect of number of CFRP layers on the axial capacity of CFRP strengthened samples.

The difference between one layer and two layers of CFRP confinement was evident. On average, one layer of CFRP confinement caused an $11.5 \%$ gain in axial capacity while two layers of CFRP confinement caused a 50\% gain in axial capacity. The number of layers increases the thickness of the CFRP confinement and seems to have the highest effect on the axial capacity of the four parameters investigated [24].

Two layers of CFRP confinement should be used when greater changes in axial capacity are required. For example, in a building being retrofitted, lower storeys that bear higher loads may have two layers of CFRP installed. In the upper storeys, where the loads are less, one layer of CFRP may be used. This optimisation of resources ensures maximum benefit at the least cost.

\subsubsection{Ductility}

The values of the ductility of the specimens are presented in Table 3.2.

Table 3.2. Results for ductility of the specimens expressed as percentages.

\begin{tabular}{|l|r|r|r|}
\hline $\begin{array}{c}\text { Specimen } \\
\text { Type }\end{array}$ & \multicolumn{1}{c|}{ C8/10 } & \multicolumn{1}{c|}{ C12/15 } & \multicolumn{1}{c|}{ C16/20 } \\
\hline $\mathbf{A}$ & 0.2 & 0.5 & 0.3 \\
\hline $\mathbf{B}$ & 0.7 & 0.3 & 0.3 \\
\hline $\mathbf{C}$ & 1.7 & 1.0 & 1.3 \\
\hline $\mathbf{D}$ & 2.4 & 0.7 & 0.9 \\
\hline $\mathbf{E}$ & 3.9 & 1.2 & 2.3 \\
\hline $\mathbf{F}$ & 4.6 & 0.7 & 0.5 \\
\hline $\mathbf{G}$ & 0.9 & 2.6 & 3.7 \\
\hline $\mathbf{H}$ & 1.5 & 2.9 & 4.1 \\
\hline $\mathbf{I}$ & 4.6 & 8.7 & 10.6 \\
\hline $\mathbf{J}$ & 6.6 & 7.1 & 7.0 \\
\hline
\end{tabular}

3.1.7 Effect of Concrete grade on the ductility of CFRP strengthened columns

The results of the ductility of the specimen of different concrete grades is presented in Figure 3.5.

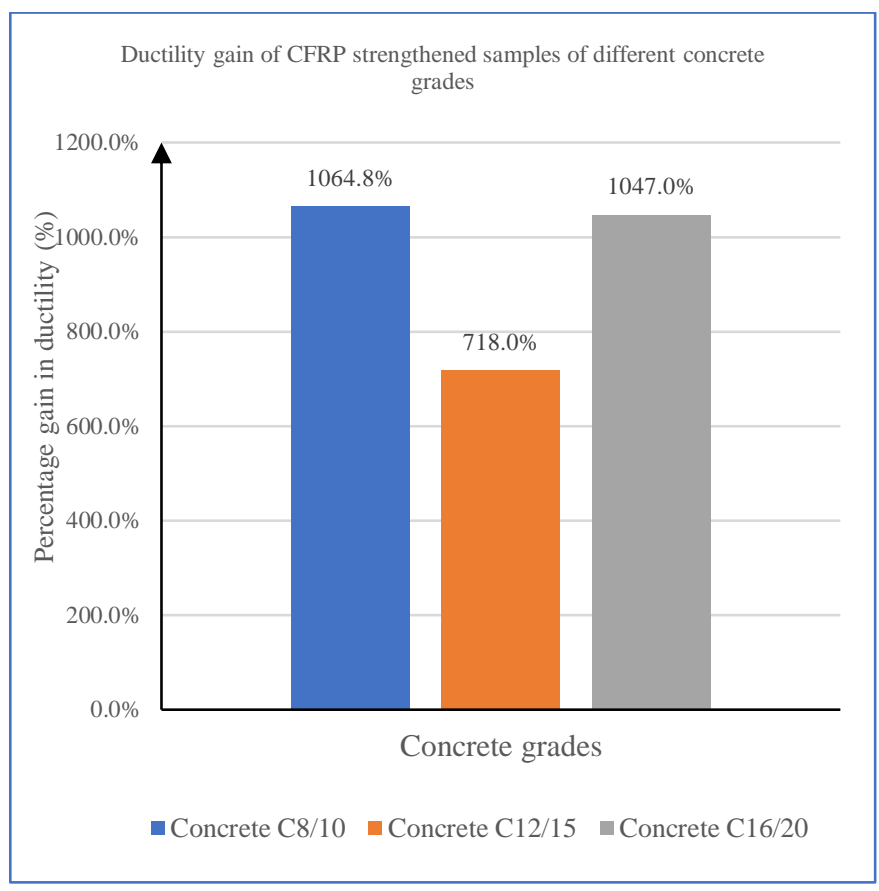

Figure 3.5. Effect of Concrete grade on the ductility of CFRP strengthened samples.

There seems to be no direct relationship between concrete grades and the ductility of the reinforced concrete columns; however, on average; Concrete C8/10 experienced $1064.8 \%$ change in ductility, Concrete $\mathrm{C} 12 / 15$ experienced $718 \%$ change while Concrete C16/20 had $1047 \%$ change. Whereas these changes seem relatively high, it is consistent with a study by Wang et al. [31] that had a 500\% increase in ductility for Concrete C25/30. That study had sophisticated sensors to measure deflections and was verified using Finite Element Analysis [31]. Masia et al. [16] also found increases in ductility of $522 \%$ for specimens of similar dimensions $(125 \mathrm{~mm} \times 125 \mathrm{~mm} \times$ $375 \mathrm{~mm})$ to the one used in this study $(150 \mathrm{~mm} \times 150 \mathrm{~mm}$ $x 350 \mathrm{~mm}$ ). Concrete $\mathrm{C} 8 / 10$ had the most considerable change in ductility caused by CFRP strengthening. This finding confirms the observations of studies by Shehata et al. [27] and Shrive et al. [11]. 


\subsubsection{Effect of rebar on ductility of CFRP strengthened columns}

To find out the effect on rebar on ductility four comparisons were made and are presented in Figure 3.6. The comparisons drawn for ductility are similar to the comparisons drawn for axial capacity in the preceding sections.

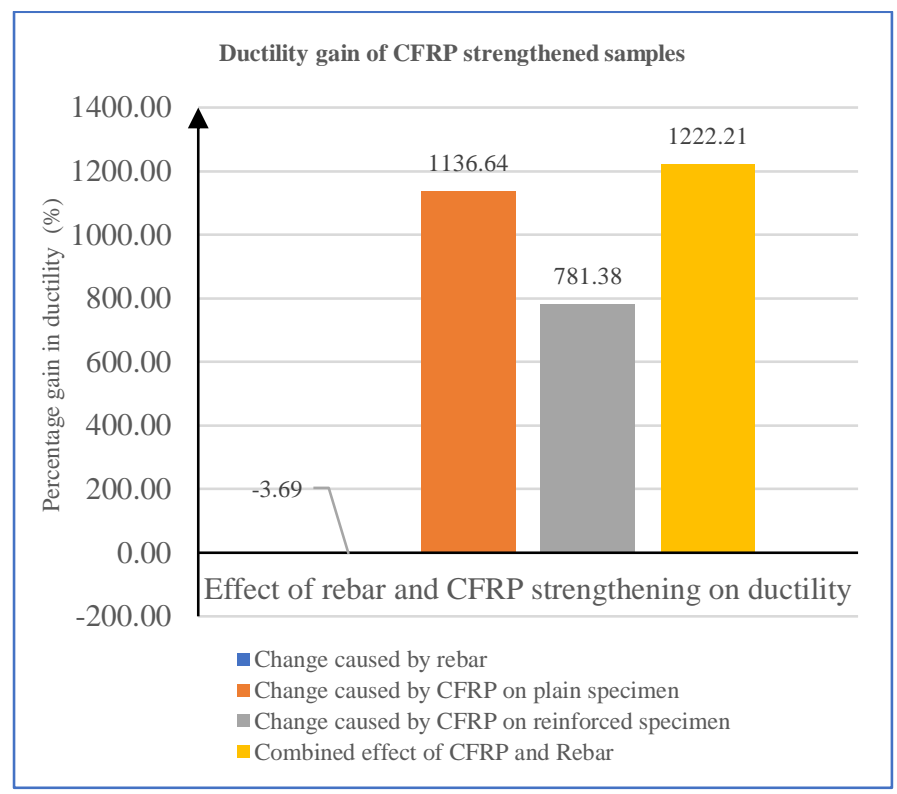

Figure 3.6. Effect of rebar and CFRP on the ductility of CFRP strengthened samples.

On average, CFRP strengthened specimens with reinforcement had $3.6 \%$ less ductility than specimens without reinforcement. This finding was contrary to the literature reviewed in this study [6], [32]. It was assumed that the confinement offered by both rebar and CFRP would be higher than confinement provided by CFRP alone. The higher confinement would thus cause an increase in the ductility of the column. The results, however, indicate different behaviour of the CFRP strengthened samples. This contrary finding may be attributed to the fact that rebar contributes to the confinement of the deforming concrete as it is loaded; there is less lateral expansion of the concrete. Less dilation of the concrete core results in less passive confinement pressure generated on the CFRP wrap. The less confinement pressure results in less ductility in reinforced concrete samples while compared to plain concrete samples that have similar CFRP configuration. In addition to that, the CFRP strengthening would make the column stiffer and therefore, less ductile. This observation is replicated in the third bar of the chart in Figure 3.6 when reinforced concrete specimen with CFRP strengthening is compared against reinforced specimens without CFRP strengthening.
3.1.9 Effect of Degree of Confinement on ductility of CFRP strengthened columns

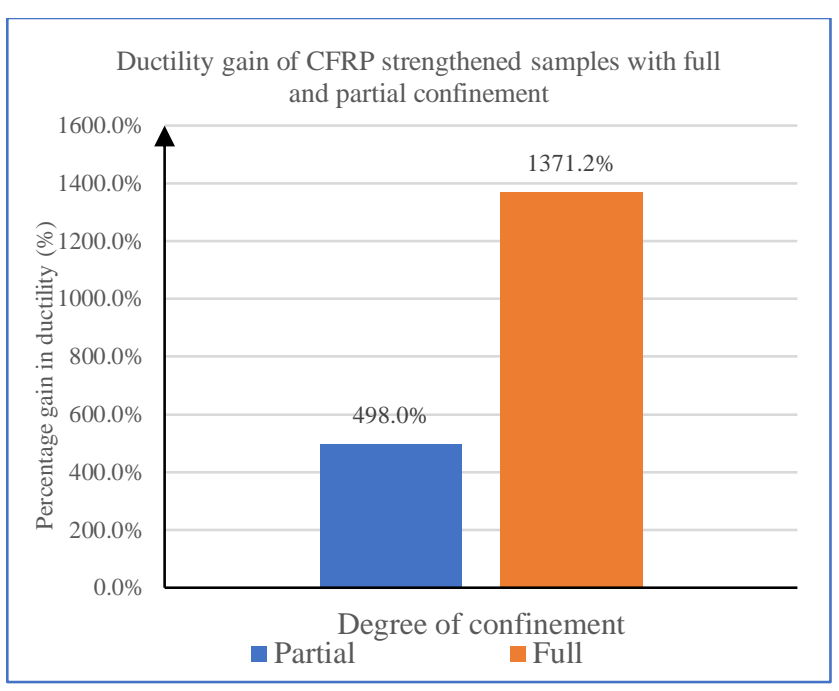

Figure 3.7. Effect of degree of confinement on the ductility of CFRP strengthened columns.

Specimens with partial CFRP confinement had an average increase of $498 \%$ in ductility. In contrast, specimens with full CFRP confinement had an average increase of $1371.2 \%$ in ductility. This finding disproves the claim that partial CFRP confinement has the same effect as full CFRP confinement in terms of ductility [23].

\subsubsection{Effect of number of layers on ductility of CFRP strengthened columns}

The results show that full CFRP confinement has a significant incremental change in the ductility of columns than partial CFRP confinement.

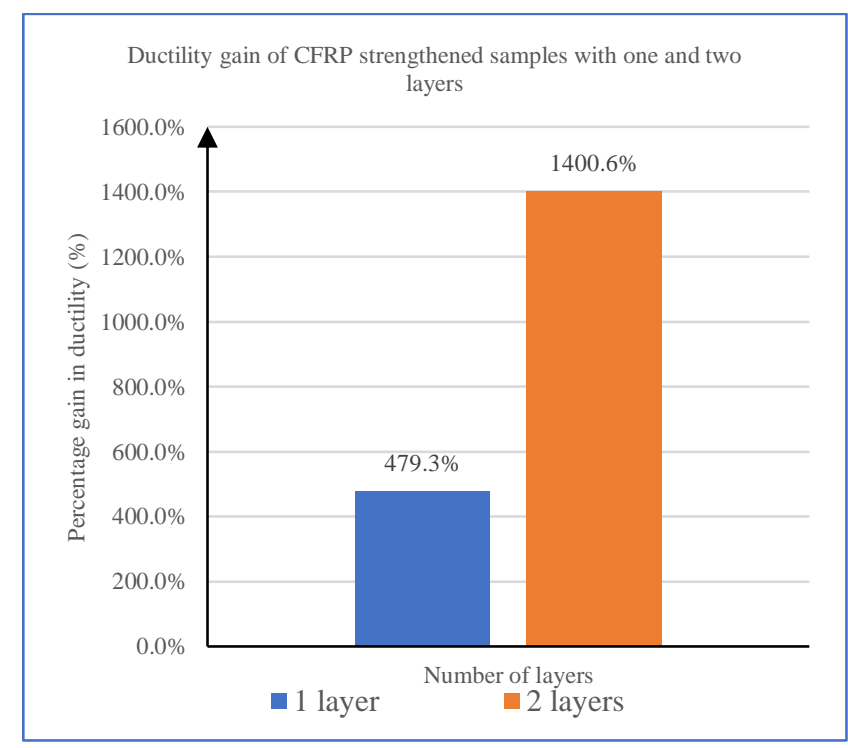

Figure 3.8. Effect of number of CFRP layers on the ductility of CFRP strengthened samples.

Specimens with partial CFRP confinement had an average increase of $498 \%$ in ductility. In contrast, specimens with full CFRP confinement had an average increase of $1371.2 \%$ in ductility. 


\section{Conclusion}

Ninety column samples with varying configurations were tested to failure, and it was found that CFRP strengthening increased the axial capacity and ductility of non-slender square concrete columns. Based on the experimental evidence, the findings of the effect of the variables investigated on CFRP strengthened columns are as follows:

1. The grade of concrete has an inverse effect on CFRP strengthening in terms of axial capacity and ductility.

2. Steel reinforcement decreases the effect of CFRP strengthening on the axial capacity and ductility of non-slender concrete columns.

3. Partial CFRP confinement offers an increase in axial capacity and ductility, although to a lesser extent than full CFRP confinement.

4. Additional number of layers increases the effect of CFRP strengthening on axial capacity and ductility.

\section{Recommendations}

1. The combined effect of rebar and CFRP on the axial capacity is the sum of the individual effect of rebar and the individual effect of CFRP strengthening.

The combined effect of rebar and CFRP

$=$ Individual effect of Rebar + Individual effect of CFRP

2. Partial CFRP confinement has greater material efficiency than full CFRP confinement. Using two layers of partial CFRP confinement is more effective than using one layer of full CFRP confinement in terms of material and the gain in axial capacity and ductility.

3. A design proposal is recommended based on the percentage gain in strength required.

\begin{tabular}{|l|l|}
\hline $\begin{array}{l}\text { Table 5.1. Recommendation on CFRP configuration required. } \\
\text { Percentage } \\
\text { Change }\end{array}$ & $\begin{array}{l}\text { Number of Layers } \\
\mathbf{1 1 0 \%}\end{array}$ \\
\hline $\mathbf{1 0 - 3 0 \%}$ & One layer partial confinement \\
\hline $\mathbf{3 0 - 5 0 \%}$ & One layer full confinement \\
\hline $\mathbf{5 0 \%}$ & Two layers partial confinement \\
\hline
\end{tabular}

\section{References}

[1] W. M. C. McKenzie, Design of Structural Elements to Eurocodes, 2nd ed. London, UK: Palgrave Macmillan, 2013.

[2] BSI, 'BS EN 12390-2:2009 - Testing Hardened Concrete', London, UK: British Standards Institute, 2009.

[3] Associated Press, 'Building collapses in Kenya, unknown number trapped in debris', South China Morning Post, Dec. 06, 2019. https://www.scmp.com/news/world/africa/article/3 040999/six-floor-building-collapses-nairobi- kenya-unknown-number-trapped (accessed Dec. 31, 2019).

[4] NCA, 'Building Audit Report', National Construction Authority (NCA), Nairobi, Kenya, 2015. Accessed: Dec. 31, 2019. [Online].

[5] C. Omullo, 'City Hall plans to demolish over 200 "unsafe" buildings', The Daily Nation, Nairobi, Mar. 22, 2018.

[6] The Concrete Society, 'Design guidance for strengthening concrete structures using fibre composite materials', The Concrete Society, Berkshire, UK, Technical Report No. 55, 2000. Accessed: Nov. 10, 2019. [Online].

[7] IQSK, 'Building Construction Cost Handbook 2018/2019', Institute of Quantity Surveyors of Kenya, Nairobi, Kenya, Handbook 2018/2019, 2019. Accessed: Jan. 14, 2020. [Online].

[8] L. Wei, Z. Ji-Hua, Z. Dong, J. Liu, M. Su, and F. Xing, 'Anodic and Mechanical Behavior of Carbon Fiber Reinforced Polymer as a Dual-Functional Material in Chloride-Contaminated Concrete', Materials, vol. 13, no. 222, 2020, doi: 10.3390/ma13010222.

[9] H. A. Abadi, V. Paton-Cole, and H.-T. Thai, 'Axial strength and elastic stiffness behaviour of partially confined concrete columns', Constr. Build. Mater., vol. 196, pp. 727-741, Jan. 2019, doi: 10.1016/j.conbuildmat.2018.11.104.

[10]A. R. Rahai, P. Sadeghian, and M. R. Ehsani, 'Experimental Behaviour of Concrete Cylinders Confined with CFRP Composites', in 14 WCEE, Beijing, China, Oct. 2008, vol. 14WCEE.

[11]P. L. Shrive, A. Azarnejad, G. Tadros, C. McWhinnie, and N. G. Shrive, 'Strengthening of concrete columns with carbon fibre reinforced polymer wrap', Can. J. Civ. Eng., vol. 30, no. 3, pp. 543-554, Jun. 2003, doi: https://doi.org/10.1139/103-007.

[12]F. E. Richart, A. Brandtzæg, and R. L. Brown, 'A study of the failure of concrete under combined compressive stresses', University of Illinois, Urbana, USA, Illinois, United States of America, Technical Report, Nov. 1928. Accessed: Jan. 25, 2020. [Online]. Available: http://hdl.handle.net/2142/4277.

[13]M. Arduini, A. D. Tommaso, O. Manfroni, S. Ferrari, and M. Romagnolo, 'The passive confinement of elements compressed in concrete with sheets of composite material', Ital. Cem. Ind., vol. 69, no. 748, pp. 836-841, 1999.

[14]K. P. Jaya and J. Mathai, 'Strengthening of RC Column using GFRP and CFRP', Lisbon, Portugal, Sep. 2012, vol. 1 of 38, Accessed: Nov. 19, 2019. [Online].

Available: http://toc.proceedings.com/24574webtoc.pdf.

[15]A. A. Khaled, K. R. Muhammed, A. A.-O. Mohammed, and A. A. H. Al-Gadhib, 'Finite Element Modelling of CFRP-Strengthened LowStrength Concrete Short Columns', Int. Congr. 
Polym. Concr., pp. 729-734, 2018, doi: https://doi.org/10.1007/978-3-319-78175-4_93.

[16]M. J. Masia, T. N. Gale, and N. G. Shrive, 'Size effects in axially loaded square-section concrete prisms strengthened using carbon fibre reinforced polymer wrapping', 2004.

[17]A. Nanni and N. M. Bradford, 'FRP jacketed concrete under uniaxial compression', Constr. Build. Mater., vol. 0, no. 2, pp. 115-124, 1995, doi: https://doi.org/10.1016/0950-0618(95)00004-Y.

[18]A. Parvin and A. S. Jamwal, 'Effects of wrap thickness and ply configuration on compositeconfined concrete cylinders', Compos. Struct., pp. 437-442, Mar. 2004, doi: 10.1016/j.compstruct.2004.02.002.

[19]A. Parvin and W. Wang, 'Behaviour of FRP Jacketed Concrete Columns under Eccentric Loading', J. Compos. Constr., vol. 5, no. 3, pp. 146-152, Aug. 2001.

[20]P. Rochette and P. Labossière, 'Axial Testing of Rectangular Column Models confined with Composites', J. Compos. Constr., vol. 4, no. 3, pp. 129-136, Aug. 2000, doi: https://doi.org/10.1061/(ASCE)10900268(2000)4:3(129).

[21] Y.-C. Guo, S.-H. Xiao, J.-W. Luo, L.-Y. Ye, and J.J. Zeng, 'Confined Concrete in Fibre-Reinforced Polymer Partially Wrapped Square Columns: Axial Compressive Behavior and Strain Distributions by a Particle Image Velocimetry Sensing Technique', Sensors, vol. 18, no. 4118, 2018, doi: $10.3390 / \mathrm{s} 18124118$.

[22] Y.-C. Guo and J.-J. Zeng, 'Behavior of Partially and Fully FRP-Confined Circularized Square Columns (CSCs) Under Axial Compression', in Proceedings of the First International Conference on Theoretical, Applied and Experimental Mechanics, 2019, vol. 5, pp. 44-49, doi: 10.1007/978-3-319-91989-8_8.

[23] Horse Construction, 'Carbon Fibre Wrap for Concrete Columns Strengthening', Dec. 23, 2019. https://www.horseen.com/index/solution/content/i d/498 (accessed Dec. 23, 2019).

[24]A. A. Mohammed, A. C. Manalo, W. Ferdous, Y. Zhuge, P. V. Vijay, and A. Q. Alkinani, 'State-ofthe-art of prefabricated FRP composite jackets for structural repair', State---Art Prefabr. FRP Compos. Jackets Struct. Repair, 2020, doi: https://doi.org/10.1016/j.jestch.2020.02.006.

[25]T. Ozbakkaloglu, 'Compressive behavior of concrete-filled FRP tube columns Assessment of critical column parameters', Eng. Struct., vol. 51, pp. 188-199, 2013, doi: http://dx.doi.org/10.1016/j.engstruct.2013.01.017.

[26]M. Saafi, H. Toutanji, and Z. Li, 'Behaviour of Concrete Columns Confined with Fibre Reinforced Polymer Tubes', ACI Mater. J., vol. 96, no. 4, Jan. 1999, doi: 10.14359/652.

[27]I. A. E. M. Shehata, L. A. V. Carneiro, and L. C. D. Shehata, 'Strength of short concrete columns confined with CFRP sheets', Mater. Struct., vol. 35, pp. 50-58, Feb. 2002, doi: https://doi.org/10.1007\%2FBF02482090.

[28]H. A. Toutanji, M. Han, and S. Matthys, 'Axial load behaviour of rectangular concrete columns confined with FRP composites.', presented at the FRPRCS-8: 8th International Symposium on Fibre Reinforced Polymer Reinforcement for Reinforced Concrete Structures, Patras, Greece, Jul. 2007, Accessed: Nov. 21, 2019. [Online]. Available: https://biblio.ugent.be/publication/425411/file/448 689.

[29]A. Mirmiran and M. Shahawy, 'Behaviour of Concrete Columns Confined by Fibre Composites', J. Struct. Eng., vol. 123, no. 5, pp. 583-590, May 1997, doi: https://doi.org/10.1061/(ASCE)07339445(1997)123:5(583).

[30]BSI, 'BS EN 12390-3:2019 Testing hardened concrete Part 3: Compressive strength of test specimens', London, UK: British Standards Institute, 2019.

[31]X. Wang, Y. Qi, Y. Sun, Z. Xie, and W. Liu, 'Compressive Behaviour of Composite Concrete Columns with Encased FRP Confined Concrete Cores', Sensors, no. 1792, pp. 1-16, Apr. 2019, doi: 10.3390/s19081792.

[32] Y. Hou, S. Cao, X. Ni, and Y. Li, 'Research on Concrete Columns Reinforced with New Developed High-Strength Steel under Eccentric Loading', Materials, vol. 12, no. 2139, pp. 1-16, Jul. 2019, doi: doi:10.3390/ma12132139.

\section{Abbreviations}

\section{Acronym Meaning}

BS British Standard

BSI British Standards Institute

CFRP Carbon Fibre Reinforced Polymer

\author{
Acronym Meaning \\ EN European Standard \\ NCA National Construction Authority
}

